\title{
A case of Tinea Faciei caused by Trichophyton benhamiae: first report in China
}

\author{
Jingwen Tan¹, Xiaoping Liu', Zhiqin Gao ${ }^{1}$, Hong Yang ${ }^{1}$, Lianjuan Yang ${ }^{1 *}$ (D) and Hai Wen ${ }^{2}$
}

\begin{abstract}
Background: Trichophyton benhamiae is a zoophilic dermatophyte that can cause tinea in humans and animals. Lesions caused by T. benhamiae tend to be highly inflammatory, and patients are often infected by animals or other patients infected with $T$. benhamiae. In this paper, we report the first case of tinea faciei caused by $T$. benhamiae in a Chinese girl who might be transmitted from a fox.

Case presentation: A 4-year-old girl from HaiNing city developed an itchy, erythematous, and annular plaque on her right face for the past 2 months. Before the lesion appeared, she was in close contact with the fur of a fox for almost 1 week. Septate hyaline hyphae were detected by direct mycological examination of the scales. Cultures grew on Sabouraud's dextrose agar (SDA) at $26^{\circ} \mathrm{C}$ for 2 weeks revealed the presence of T. mentagrophytes. A molecular sequencing test confirmed that the isolate was consistent with reference strains to T. benhamiae. Then, the diagnosis of tinea faciei due to T. benhamiae was made. Treatment with terbinafine (oral $125 \mathrm{mg} / \mathrm{d}$ ) and sertaconazole nitrate cream (topical, twice daily) for 4 weeks was initiated and achieved significant improvement of the skin lesions.
\end{abstract}

Conclusions: This rare dermatophytosis case highlights the importance of ITS sequencing in helping to recognize rare pathogenic fungi that can be easily misdiagnosed with a conventional morphological diagnosis.

Keywords: Trichophyton benhamiae, Tinea faciei, Terbinafine, Fox, Case report

\section{Background}

Trichophyton benhamiae is a zoophilic dermatophyte that can cause highly inflammatory tinea in humans and animals [1]. Guinea pigs are the primary carrier, and other small animals are occasionally a source of infection [2]. Due to the increased variety of pets, T. benhamiae infection is rising. Cases caused by T. benhamiae infection had been reported in several countries such as Japan, Germany, or Switzerland [1]. In Germany, T. benhamiae is the most prevalent pathogen causing zoophilic dermatophytosis, especially in children [3]. Here we report a case of tinea faciei caused by $T$. benhamiae that might have been transmitted by a fox. To the best of our knowledge, this is the first report of dermatophytosis caused by $T$. benhamiae in China.

\footnotetext{
* Correspondence: zhy52808290@qq.com

'Department of Medical Mycology, Shanghai Dermatology Hospital,

Shanghai 200443, China

Full list of author information is available at the end of the article
}

\section{Case presentation}

A 4-year-old girl from HaiNing city developed an itchy, erythematous, and annular plaque on her right face for the past 2 months. The lesion was initially tiny erythema with scale. Topical clobetasol propionate ketoconazole cream was administered for 15 days without any response. The treatment was switched to pimecrolimus and hydrocortisone butyrate cream, but the lesion became lightly tender, itchy, and transforming into a "ring" erythematous plaque. The patient attended to our clinic in December 2018. Her mother denied any previous history of trauma. A remarkable antecedent was the fact that her family feeds foxes as a source of income. Before the lesion appeared, she was in close contact with the fur of a fox for almost 1 week. The rest of her medical and family history was unremarkable.

The physical examination showed a $3 \mathrm{~cm} \times 5 \mathrm{~cm}$ erythematous annular plaque on her right face covered 


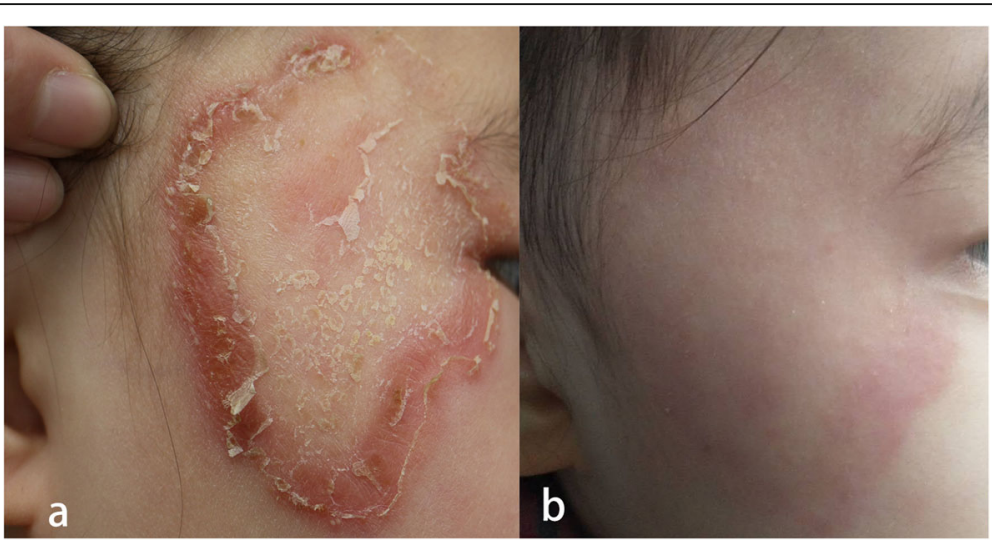

Fig. 1 Clinical appearance. a Annular plaque with erythema covered with scales and crusts $(3 \mathrm{~cm} \times 5 \mathrm{~cm})$ on the right face. b Complete resolution of the plaque with residual erythema after 4 weeks of treatment with terbinafine (oral, $125 \mathrm{mg} / \mathrm{d}$ )

with scales and crusts (Fig. 1a). Regional lymph nodes were not palpable. Direct mycological examination by lesion scraping with $10 \% \mathrm{KOH}$ showed the presence of septate hyaline hyphae. A sample was cultured on sabouraud's dextrose agar $(\mathrm{SDA})$ at $26^{\circ} \mathrm{C}$ for 2 weeks that yielded white colonies peripherally radiating,

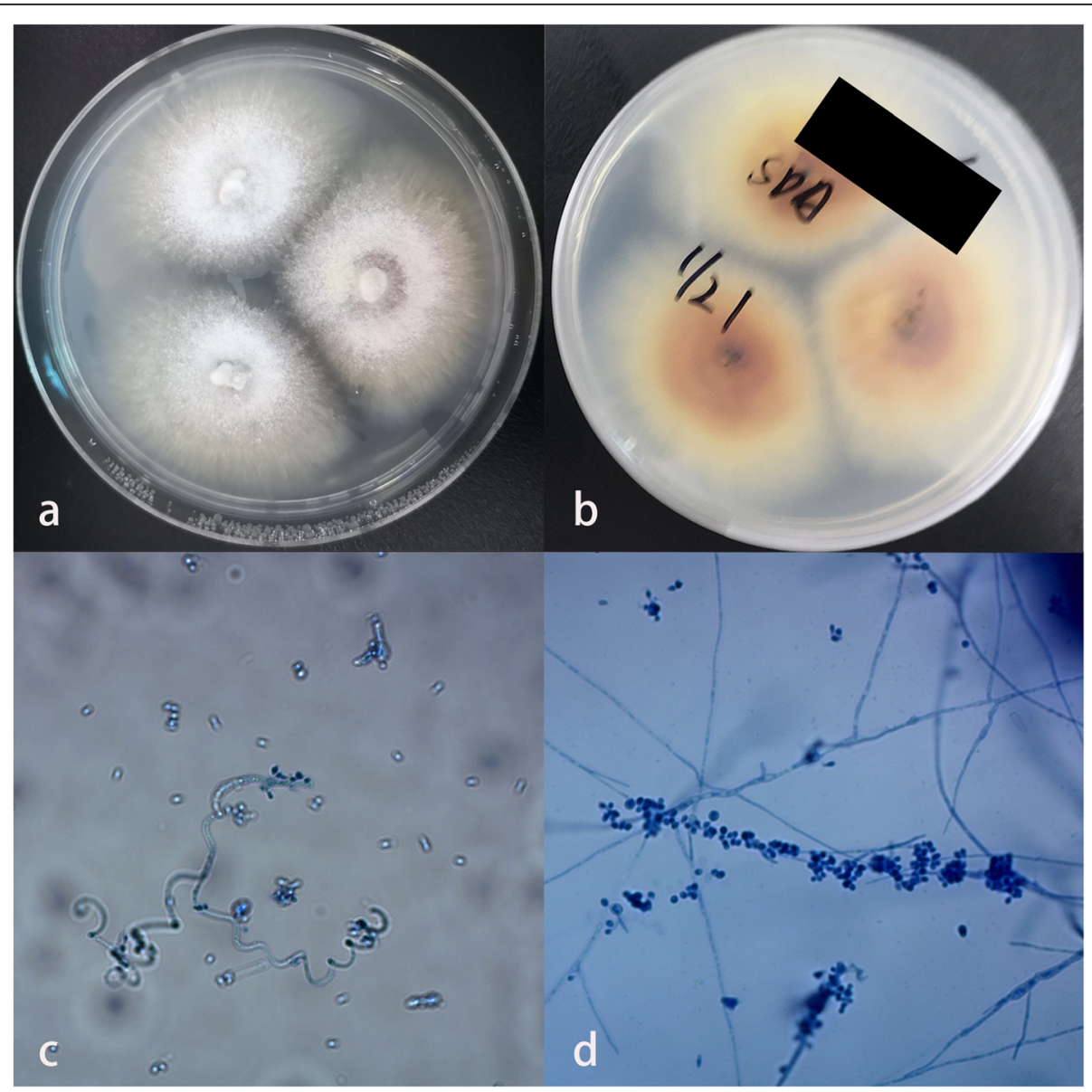

Fig. 2 Mycological findings. a and $\mathbf{b}$ Culture on SDA at $26^{\circ} \mathrm{C}$ after 2 weeks yielded white colonies, peripherally radiating, centrally raised, and powdery margins. The reverse side showed yellow to brown colonies. c Lactophenol cotton blue stain revealed filamentous and spiral hyphae (original magnification $\times \mathbf{2 0 0}$ ). $\mathbf{d}$ Lactophenol cotton blue stain revealed a grape-like arrangement of microconidia laterally and terminally inserting at the hyphae (original magnification $\times 200$ ) 
centrally raised, and powdery margins (Fig. 2a). The reverse side showed colonies with a color yellow to brown (Fig. 2b). Slides from the culture showed filamentous and spiral hyphae with a grape-like arrangement of the microconidia laterally and terminally inserting at the hyphae (Fig. 2c, d). Based on the morphological characteristics, the isolate was identified as T. mentagrophytes. Then molecular sequencing of the internal transcribed spacer (ITS) region gene was performed. Briefly, genomic DNA extracted from the culture employing Ezup Column Fungi Genomic DNA Purification Kit (Sangong Biotech, Shanghai) according to the manufacturer's instructions. Then PCR reaction was carried out to amplify the ITS Region with the following primers: ITS1 (5'TCCGTAGGTGAACCTGCGG) and ITS4 (5'-TCCTCCGCTTATTG ATATGC). Amplification was performed on a Veriti (Applied Biosystem) with following conditions: denaturation at $94{ }^{\circ} \mathrm{C}$ for $5 \mathrm{~min}$, followed by 30 cycles of $94{ }^{\circ} \mathrm{C}$ for $30 \mathrm{~s}, 54{ }^{\circ} \mathrm{C}$ for $30 \mathrm{~s}, 72^{\circ} \mathrm{C}$ for 60 s, and finally an extension $72^{\circ} \mathrm{C}$ for $8 \mathrm{~min}$. After verified by electrophoresis on $1.0 \%$ agarose gels, the PCR-amplified product was sent to Sangon Biotech (Shanghai) for sequencing. Sequence of this isolate determined in this study was aligned with reference sequences in genbank (https://blast.ncbi.nlm.nih.gov/Blast.cgi). A comparison of the ITS (648 bp) (genbank accession number MN536486) sequence with the genbank database revealed $100 \%$ similarity with $T$. benhamiae reference strain ATCC42873 (genbank accession number KX092365.1). The fungal culture was finally identified as $T$. benhamiae. The girl was diagnosed with tinea faciei caused by $T$. benhamiae.

In vitro susceptibility was tested following the Clinical and Laboratory Standards Institute (CLSI) M38-A2 protocol [4]. The minimum inhibitory concentration (MIC) was determined by $100 \%$ inhibition compared with the growth control. The results revealed that all the tested drugs were susceptible to the isolate. The MIC values was $4 \mu \mathrm{g} / \mathrm{ml}$ for fluconazole (FLZ), $1 \mu \mathrm{g} / \mathrm{ml}$ for itraconazole (ITC), $0.6 \mu \mathrm{g} /$ $\mathrm{ml}$ for voriconazole (VRC) and posaconazole (POS), $1 \mu \mathrm{g}$ $/ \mathrm{ml}$ for caspofungin (CAS), and $0.015 \mu \mathrm{g} / \mathrm{ml}$ for terbinafine (TRB). Oral administration of terbinafine $(125 \mathrm{mg} /$ day) and topical sertaconazole nitrate cream (twice daily) was initiated, significant improvement of the lesions was achieved after 4 weeks of treatment. No adverse event was reported.

\section{Discussion and conclusions}

T. benhamiae (previously know as Arthroderma benhamiae) was first described as teleomorph of the $T$. mentagrophytes complex in 1967 [5]. In the latest dermatophyte taxonomy based on the sequencing of the ITS ribosomal DNA region, Trichophyton sp. of $A$. benhamiae does not belong to the T. mentagrophytes complex anymore; it became T. benhamiae [6].

The first human tinea corporis caused by this fungus was reported in 1975; it was a case of a lab worker that got a hand infection after contact with an infected hedgehog three times in 3 weeks [7]. Since then, $T$. benhamiae has been diagnosed more frequently around the world. Until now, there are 30 human case reports of $T$. benhamiae infection confirmed by molecular methods (Table 1). Interestingly, $30 \%$ of them $(10 / 30)$ were family members or lived together. The patients'age ranged from 19 months to 53 years old and were spread in three continents (Asia, Europe, and South America). 18/29 of them were under 18 years old, and Tinea corporis was the most common type $(15 / 30)$ followed by Tinea faciei (13/30). Guinea pigs are the most common source $(16 / 28)$ of this pathogen, followed by other small animals such as rabbits, cats, and dogs. In this case, the infection source was from a fox. Even though foxes can be a host of $T$. benhamiae, there was no previous report of human infection by fox until now [23].

This pathogen had white and yellow phenotypes, which can difficult its identification [24]. The micromorphology of yellow colonies is downy with a pleated mycelium and a slow growth rate. They can have a rough-walled and spindle-like macroconidia. The most common differential diagnosis of the yellow phenotype is Microsporum canis. The micromorphology of white colonies is powdery to floccose, and with a rapid growth rate. Microconidia and macroconidia are numerous, and spiral hyphae are occasionally present. The primary differential diagnosis is T. mentagrophytes. In our case, the culture on SDA showed white colonies with peripherally radiating, centrally raised, and powdery margins. The slides culture revealed filamentous and spiral hyphae with a grape-like arrangement of microconidia laterally and terminally inserting at the hyphae. Using morphology identification of the isolate, we hardly distinguished it from T. mentagrophytes. Molecular identification is the best way of identification. Though the in house instrument such as PCR instrument is a high capital cost, it is still an inexpensive assay with high specificity. In our case, the diagnosis of $T$. benhamiae infection was made through molecular methods. The incidence rate of $T$. benhamiae might be severely underestimated in China, considering the high possibility of a missed diagnosis due to morphology identification, the unusual use of molecular identification in the clinic, and no previous report of $T$. benhamiae.

The treatment of $T$. benhamiae infection was consistent with other dermatophytoses [1]. Terbinafine is 
Table 1 Cases of T. benhamiae infection confirmed with molecular sequencing

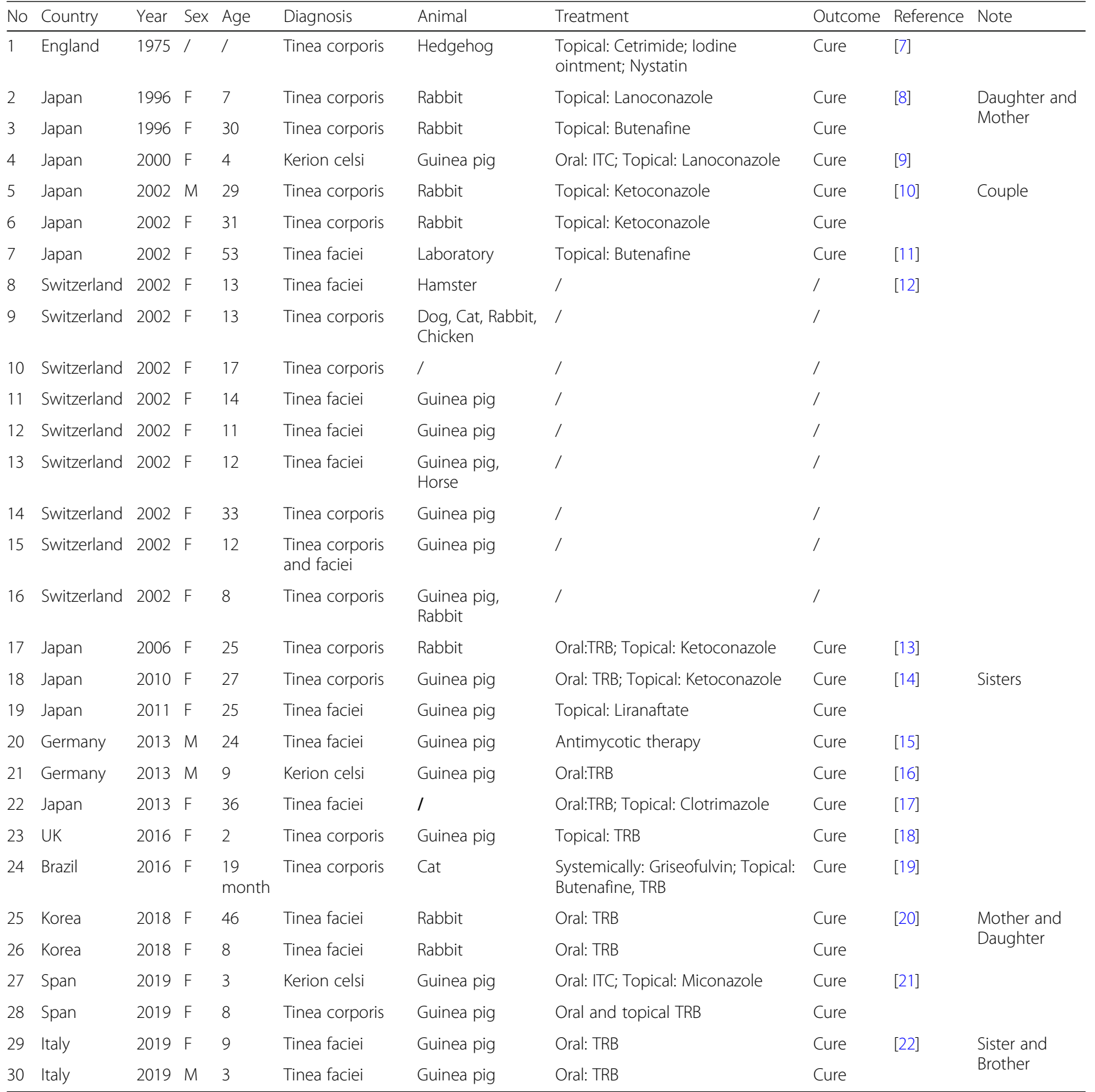

/ Undetected, $F$ Female, $M$ Male, ITC Itraconazole, TRB Terbinafine

the first line of choice, with fluconazole and itraconazole being valid alternatives. In our case, the isolate was susceptible to all the tested antifungal drugs, and oral terbinafine treatment was sufficient (Fig. 1b).

In conclusion, $T$. benhamiae is an emerging zoophilic dermatophyte with an underestimated infection rate. It can cause highly inflammatory human infections, especially in children in contact with the fur of small animals. To avoid misdiagnosis with $M$. canis or T. mentagrophytes, specific ITS-based PCR for $T$. benhamiae identification might be necessary. Once diagnosed, the use of terbinafine is highly recommended to achieve optimal outcomes.

\section{Abbreviations}

CAS: Caspofungin; FLZ: Fluconazole; ITC: Itraconazole; MIC: Minimum inhibitory concentration; POS: Posaconazole; SDA: Sabouraud's dextrose agar; TRB: Terbinafine; VRC: Voriconazole

\section{Acknowledgements}

We thank the patient for granting permission to publish this information. 


\section{Authors' contributions}

ZG and HY collected and interpreted the clinical data. JT and LY designed, interpreted the clinical data and wrote the manuscript. LY and HW revised the manuscript critically for important content. JT and XL carried out the microbiological examination and nucleotide sequencing. All authors read and approved the final manuscript.

\section{Funding}

This report received no specific grant from any funding agency in the public, commercial, or not-for-profit sectors.

\section{Availability of data and materials}

All data generated or analyzed during this study are included in this published article. The sequence data have been deposited in the GenBank database (http://www.ncbi.nlm.nih.gov/Genbank/index.html) with the accession number MN536486.

\section{Ethics approval and consent to participate}

Due approval from the Institutional Research and Ethics Committee of Shanghai dermatology hospital was obtained for analysing the case study and writing the manuscript.

\section{Consent for publication}

Written informed consent was obtained from the parents of the patient described in this report. A copy of the written consent is available by request.

\section{Competing interests}

The authors declare that they have no competing interests.

\section{Author details}

'Department of Medical Mycology, Shanghai Dermatology Hospital, Shanghai 200443, China. ${ }^{2}$ Department of Dermatology, Shanghai Changzheng Hospital, Second Affiliated Hospital of Naval Military Medical University, Shanghai 200003, China.

\section{Received: 5 December 2019 Accepted: 17 February 2020}

Published online: 22 February 2020

\section{References}

1. Nenoff P, Uhrlass S, Kruger C, Erhard M, Hipler UC, Seyfarth F, Herrmann J, Wetzig T, Schroedl W, Graser Y. Trichophyton species of Arthroderma benhamiae - a new infectious agent in dermatology. J Dtsch Dermatol Ges. 2014;12(7):571-81.

2. Tekin HG, Sigsgaard V, Zachariae C, Hare RK, Arendrup MC, Saunte DML. Would you like to purchase a rodent with dermatophytes? Mycoses. 2019; 62(7):584-7.

3. Brasch J, Wodarg S. Morphological and physiological features of Arthroderma benhamiae anamorphs isolated in northern Germany. Mycoses. 2015:58(2):93-8.

4. Clinical and Laboratory Standards Institute. Reference method for broth dilution antifungal susceptibility testing of filamentous fungi; approved standard-2nd ed, CLSI document M38-A2. Wayne, PA: CLSI; 2008.

5. Ajello L, Cheng SL. The perfect state of Trichophyton mentagrophytes. Sabouraudia. 1967:5(3):230-4.

6. de Hoog GS, Dukik K, Monod M, Packeu A, Stubbe D, Hendrickx M, Kupsch C, Stielow JB, Freeke J, Goker M, Rezaei-Matehkolaei A, Mirhendi H, Gräser Y. Toward a novel multilocus phylogenetic taxonomy for the Dermatophytes. Mycopathologia. 2017;182(1-2):5-31.

7. Gregory MW, English MP. Arthroderma benhamiae infection in the Central African hedgehog Erinaceus albiventris, and a report of a human case. Mycopathologia. 1975;55(3):143-7.

8. Kawasaki M, Aso M, Inoue T, Ohsawa T, Ishioka S, Mochizuki T, Ishizaki H. Two cases of tinea corporis by infection from a rabbit with Arthroderma benhamiae. Nihon Ishinkin Gakkai Zasshi. 2000;41(4):263-7.

9. Hattori N, Kaneko T, Tamaki K, Makimura K, Mochizuki T. A case of kerion celsi due to Arthroderma benhamiae identified by DNA sequences of nuclear ribosomal internal transcribed spacer 1 regions. Med Mycol. 2003; 41(3):249-51.
10. Nakamura Y, Kano R, Nakamura E, Saito K, Watanabe S, Hasegawa A. Case report. First report on human ringworm caused by Arthroderma benhamiae in Japan transmitted from a rabbit. Mycoses. 2002;45(3-4):129-31.

11. Mochizuki T, Watanabe S, Kawasaki M, Tanabe H, Ishizaki H. A Japanese case of tinea corporis caused by Arthroderma benhamiae. J Dermatol. 2002;29(4): 221-5.

12. Fumeaux J, Mock M, Ninet B, Jan I, Bontems O, Lechenne B, Lew D, Panizzon RG, Jousson O, Monod M. First report of Arthroderma benhamiae in Switzerland. Dermatology. 2004;208(3):244-50

13. Shiraki Y, Hiruma M, Matsuba Y, Kano R, Makimura K, Ikeda S, Ogawa H. A case of tinea corporis caused by Arthroderma benhamiae (teleomorph of Tinea mentagrophytes) in a pet shop employee. J Am Acad Dermatol. 2006; 55(1):153-4

14. Mochizuki T, Kobayashi H, Takeda K, Anzawa K, Ishizaki H. The first human cases of Americano-European race of Arthroderma benhamiae infection in Japan. Jpn J Infect Dis. 2012;65(6):558-9.

15. Braun SA, Jahn K, Westermann A, Bruch-Gerharz D, Reifenberger J. Tinea barbae profunda by Arthroderma benhamiae. A diagnostic challenge. Hautarzt. 2013;64(10):720-2.

16. Nenoff P, Schulze I, Uhrlass S, Kruger C. Kerion caused by the zoophilic dermatophyte Trichophyton species of Arthroderma benhamiae in a child. A new emerging pathogen of dermatomycoses in Germany. Hautarzt. 2013; 64(11):846-9.

17. Kimura U, Yokoyama K, Hiruma M, Kano R, Takamori K, Suga Y. Tinea faciei caused by Trichophyton mentagrophytes (molecular type Arthroderma benhamiae ) mimics impetigo : a case report and literature review of cases in Japan. Med Mycol J. 2015;56(1):E1-5,

18. El-Heis S, Borman AM, Szekely A, Godfrey KM. Tinea corporis caused by Arthroderma benhamiae in a child. Clin Exp Dermatol. 2016;41(8):955-7.

19. de Freitas RS, de Freitas THP, Siqueira LPM, Gimenes VMF, Benard G. First report of tinea corporis caused by Arthroderma benhamiae in Brazil. Braz 」 Microbiol. 2019;50(4):985-7.

20. Lee WJ, Eun DH, Jang YH, Lee SJ, Bang YJ, Jun JB. Tinea Faciei in a mother and daughter caused by Arthroderma benhamiae. Ann Dermatol. 2018;30(2): 241-2.

21. Martin-Penaranda T, Lera Imbuluzqueta JM, Alkorta GM. Arthroderma benhamiae in patients with Guinea pigs. An Pediatr (Barc). 2019:90(1):51-2.

22. Giovannini M, Oranges T, Dolce D, de Martino M, Filippeschi C, Bassi A. Unusual cases of paediatric tinea faciei transmitted by Guinea pigs. Arch Dis Child. 2019;0:1. https://doi.org/10.1136/archdischild-2019-317415.

23. Ziolkowska G, Nowakiewicz A, Gnat S, Troscianczyk A, Zieba P, Dziedzic BM. Molecular identification and classification of Trichophyton mentagrophytes complex strains isolated from humans and selected animal species. Mycoses. 2015;58(3):119-26.

24. Sabou M, Denis J, Boulanger N, Forouzanfar F, Glatz I, Lipsker D, Poirier P, Candolfi E, Letscher-Bru V. Molecular identification of Trichophyton benhamiae in Strasbourg, France: a 9-year retrospective study. Med Mycol. 2018;56(6):723-4.

\section{Publisher's Note}

Springer Nature remains neutral with regard to jurisdictional claims in published maps and institutional affiliations.

Ready to submit your research? Choose BMC and benefit from:

- fast, convenient online submission

- thorough peer review by experienced researchers in your field

- rapid publication on acceptance

- support for research data, including large and complex data types

- gold Open Access which fosters wider collaboration and increased citations

- maximum visibility for your research: over $100 \mathrm{M}$ website views per year

At $\mathrm{BMC}$, research is always in progress.

Learn more biomedcentral.com/submissions 